\title{
Solid-Phase Synthesis of 1,3-Azole-Based Peptides and Peptidomimetics
}

\author{
Eric Biron, Jayanta Chatterjee, and Horst Kessler* \\ Department Chemie, Lehrsthul II für Organische Chemie, Technische Universität München, \\ Lichtenbergstrasse 4, Garching D-85747, Germany \\ Horst.Kessler@ch.tum.de
}

SUPPORTING INFORMATION

PART B

NMR analyses of compound 4a-d, 6a-d, 10a-d, 14a,b, 17a,b and 18-22

S26-S45 


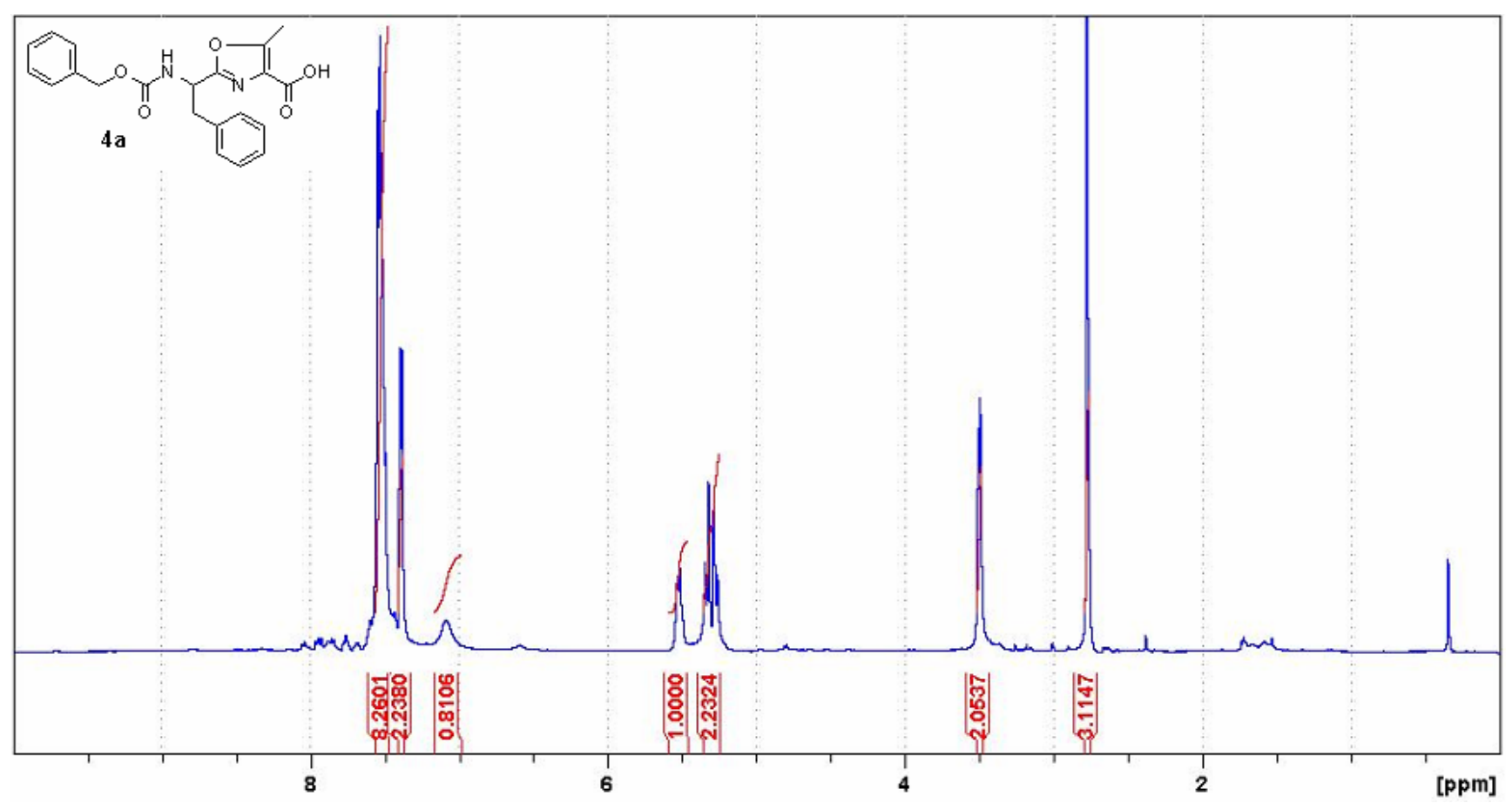

${ }^{1} \mathrm{H}$ NMR spectrum of compound $\mathbf{4 a}$ in $\mathrm{CDCl}_{3}$

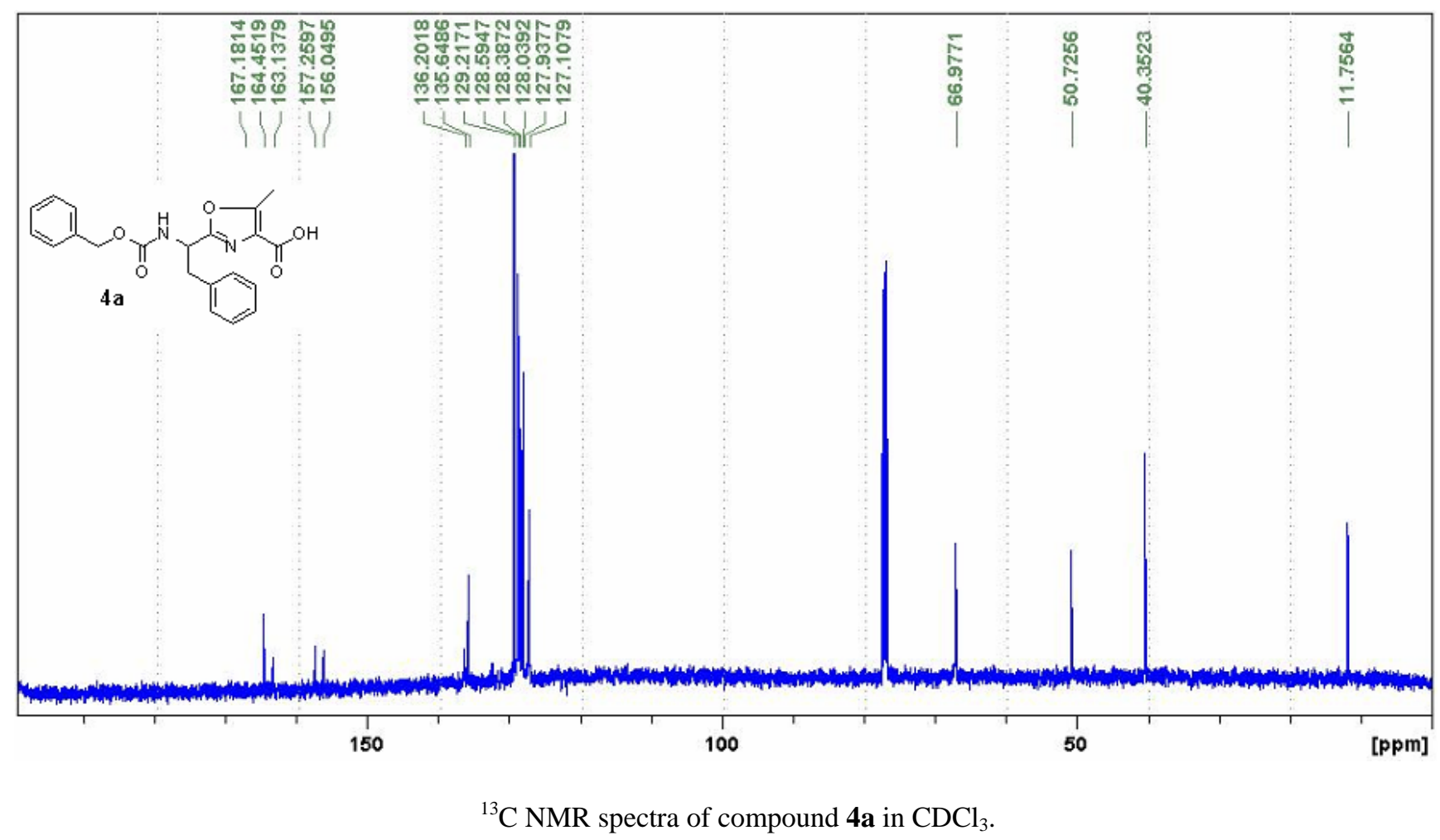




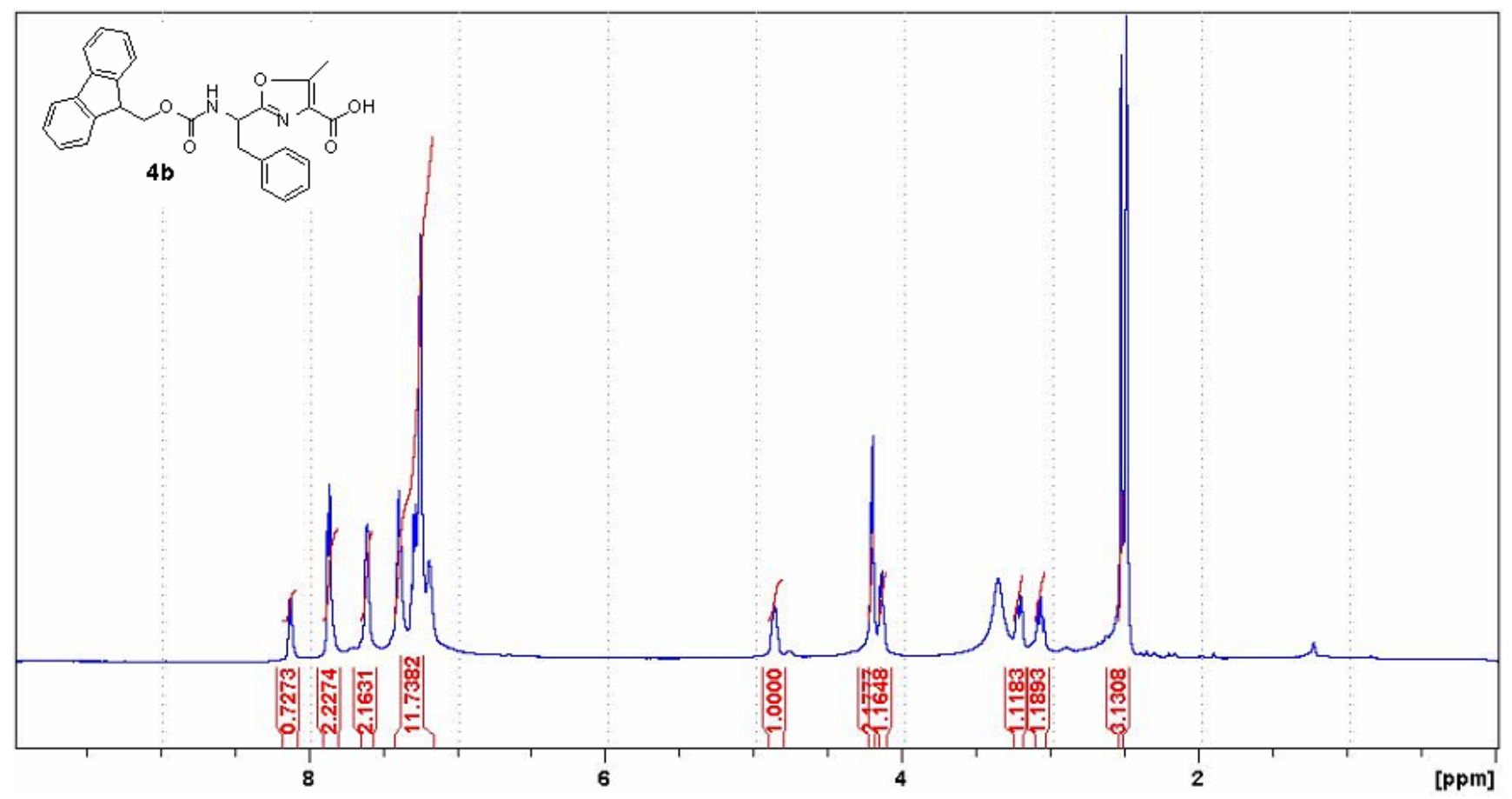

${ }^{1} \mathrm{H}$ NMR spectrum of compound $\mathbf{4 b}$ in DMSO- $\mathrm{d}_{6}$.

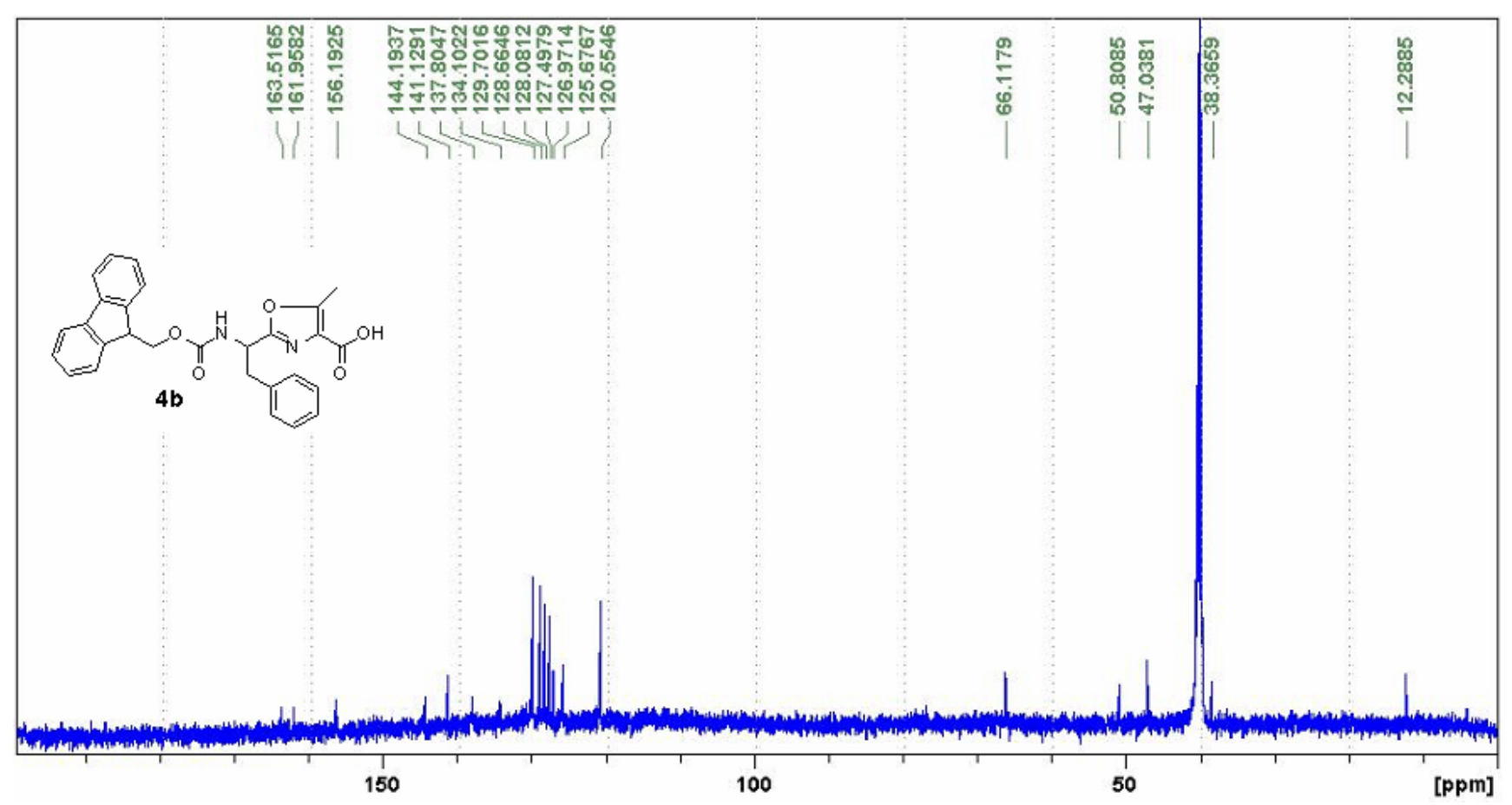

${ }^{13} \mathrm{C}$ NMR spectra of compound $\mathbf{4} \mathbf{b}$ in DMSO- $\mathrm{d}_{6}$. 


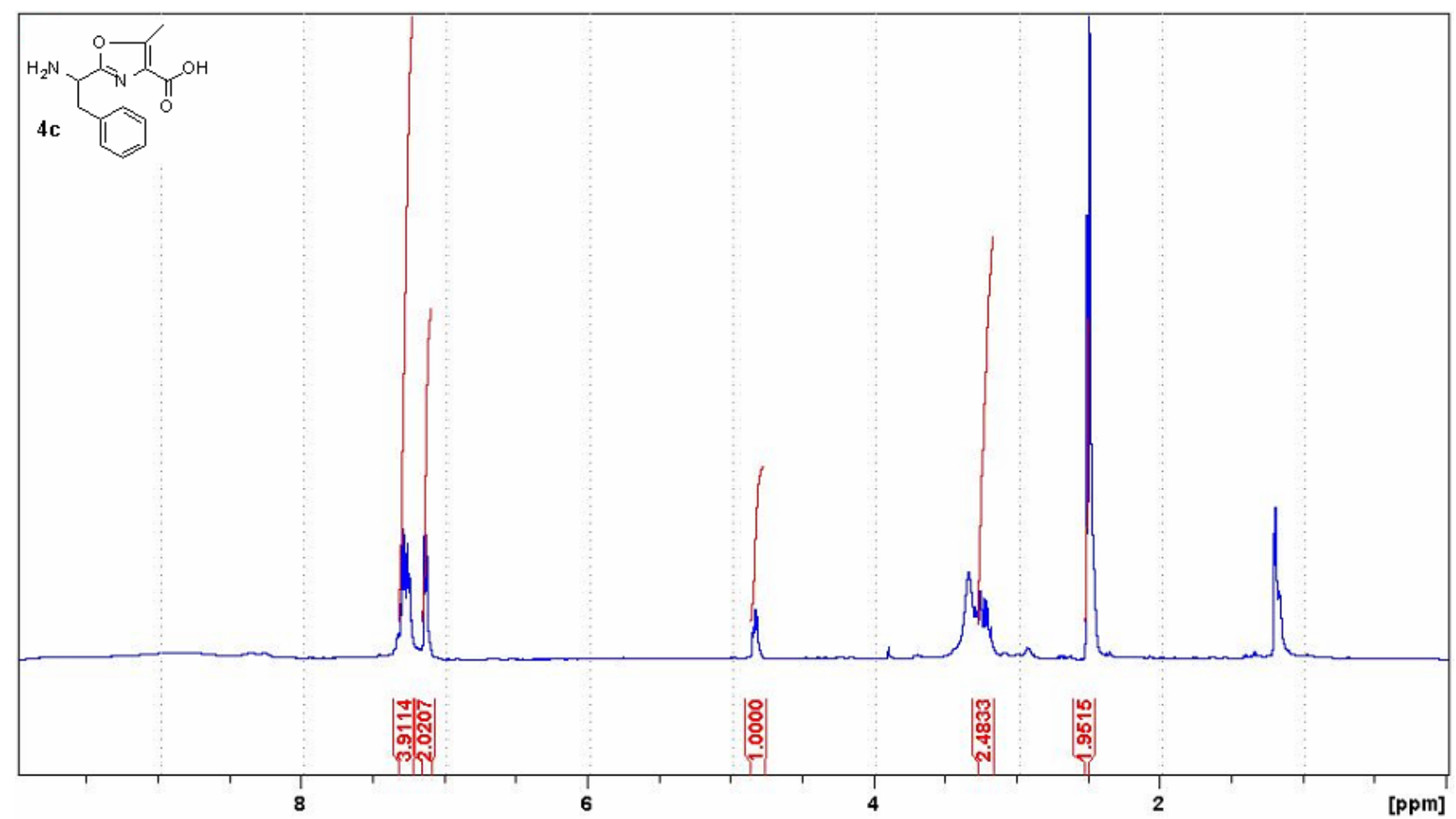

${ }^{1} \mathrm{H}$ NMR spectrum of compound $\mathbf{4 c}$ in DMSO- $\mathrm{d}_{6}$.

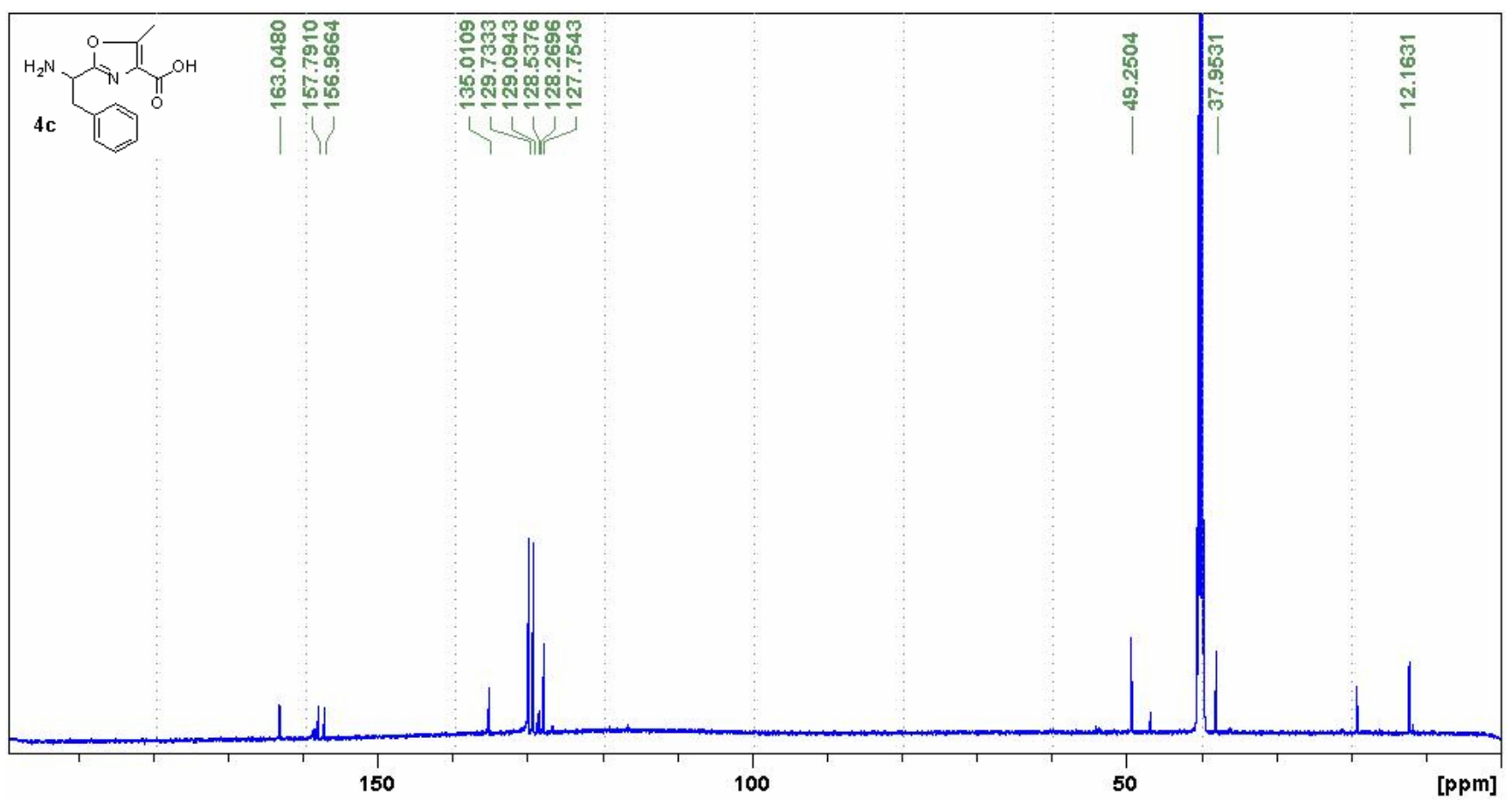

${ }^{13} \mathrm{C}$ NMR spectra of compound $4 \mathrm{c}$ in DMSO- $\mathrm{d}_{6}$. 

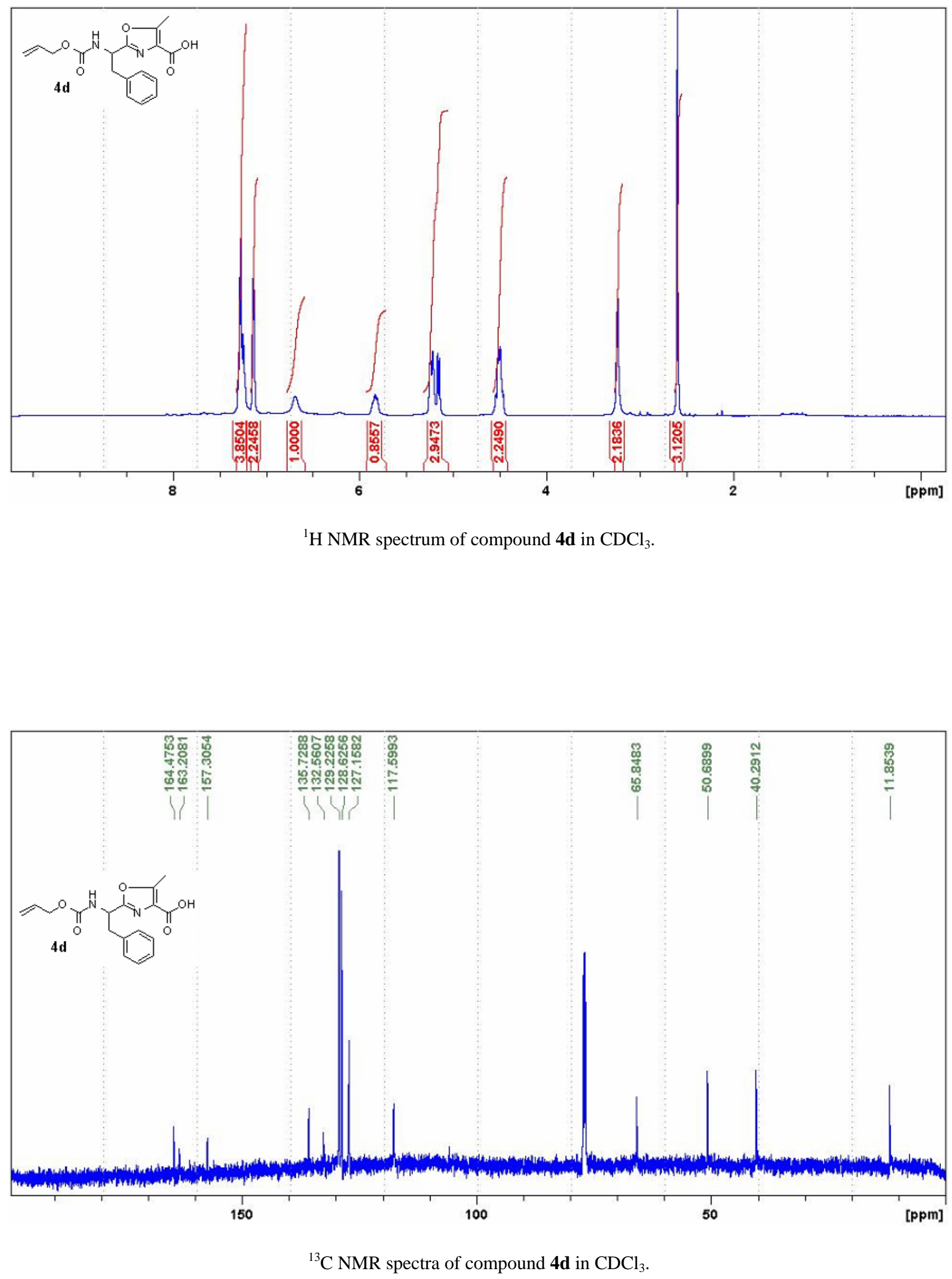

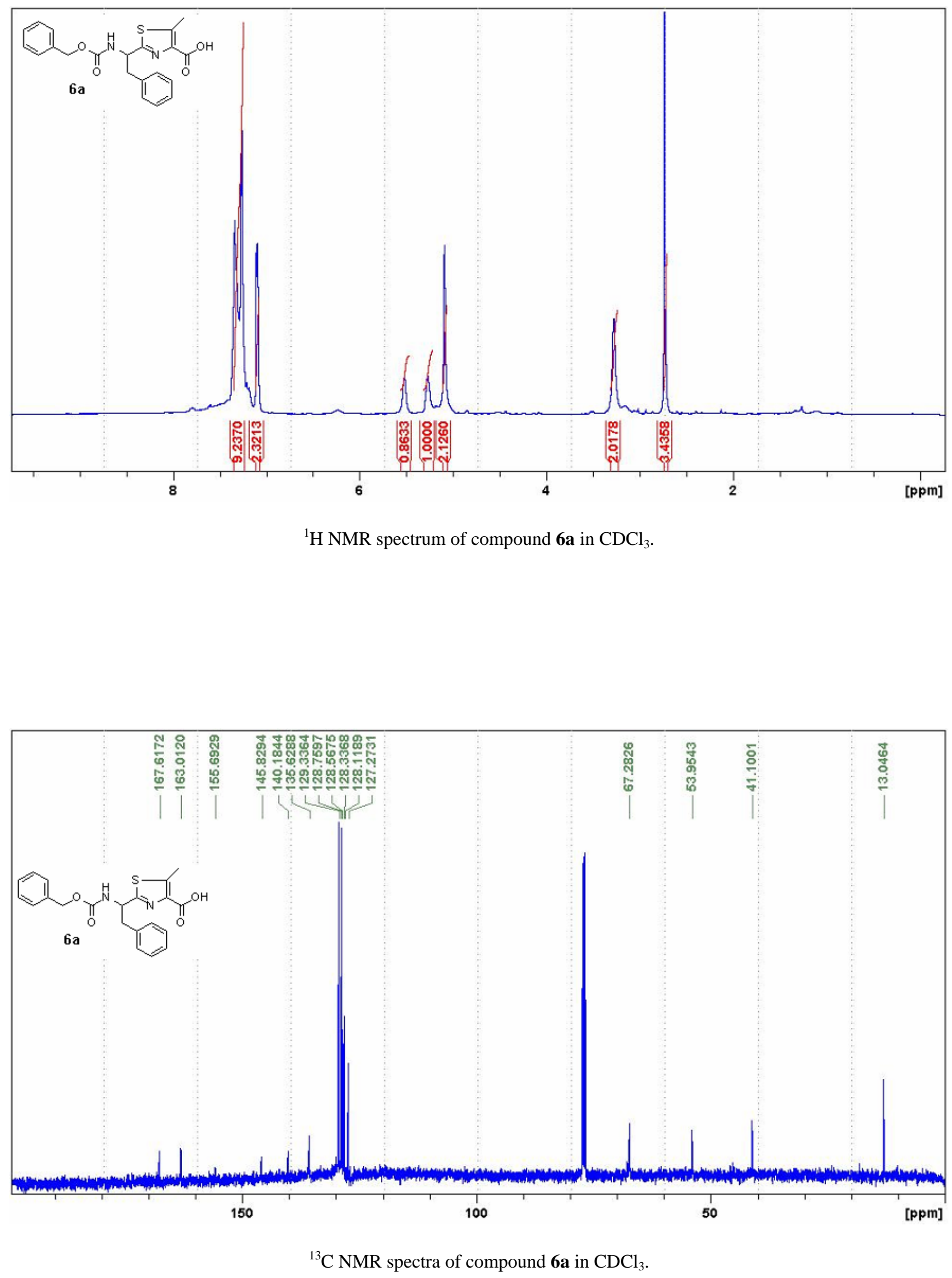

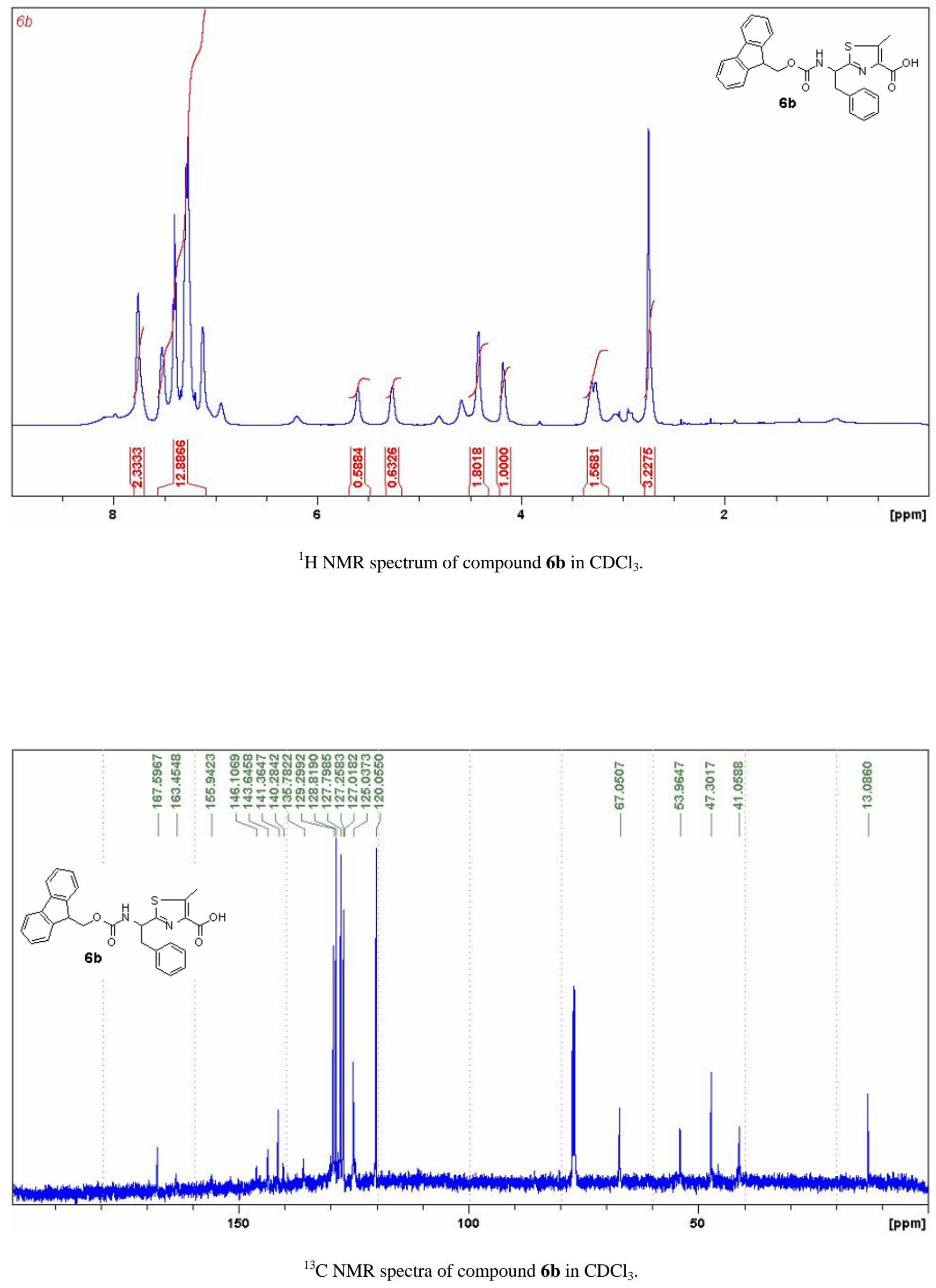

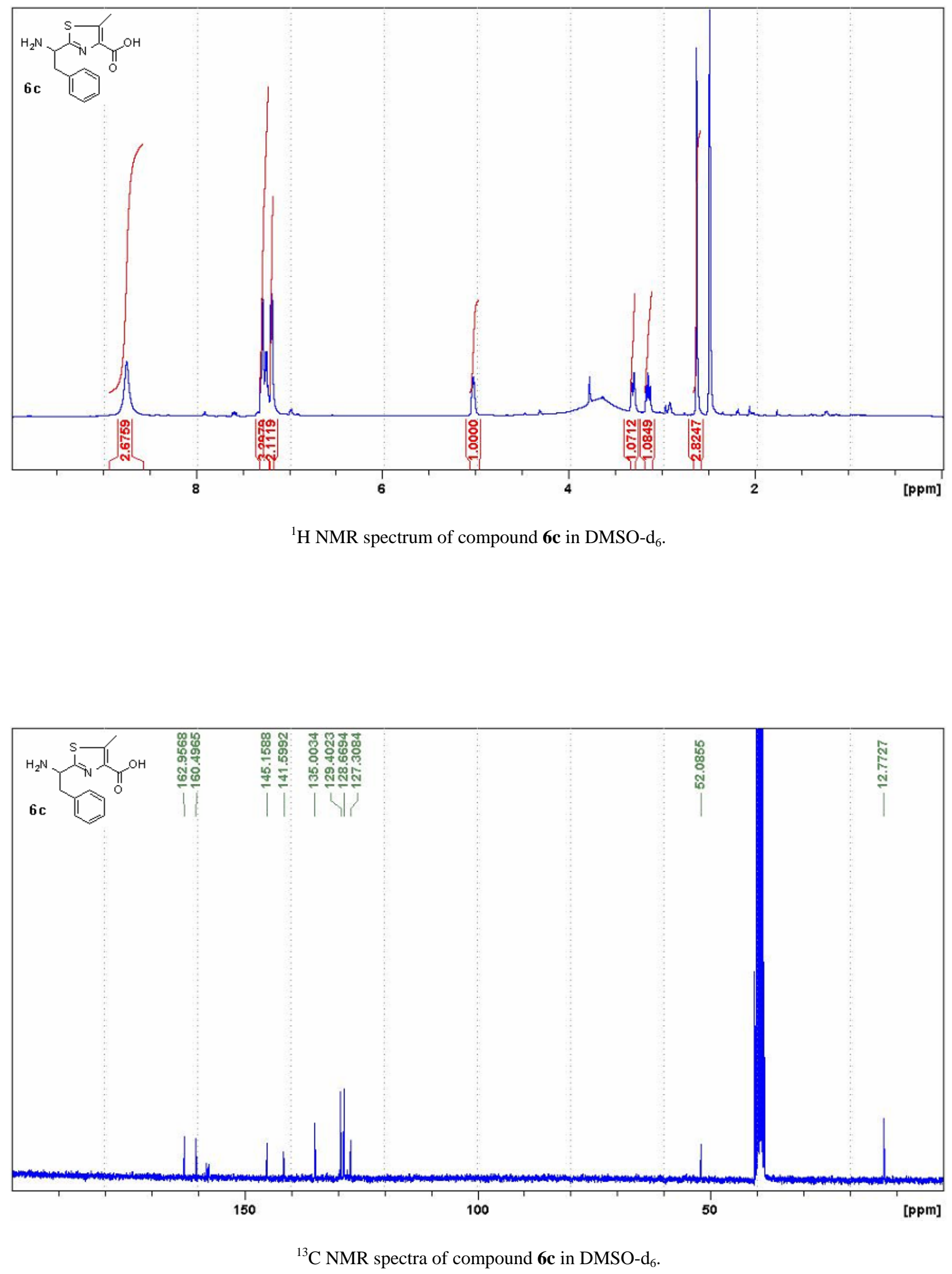

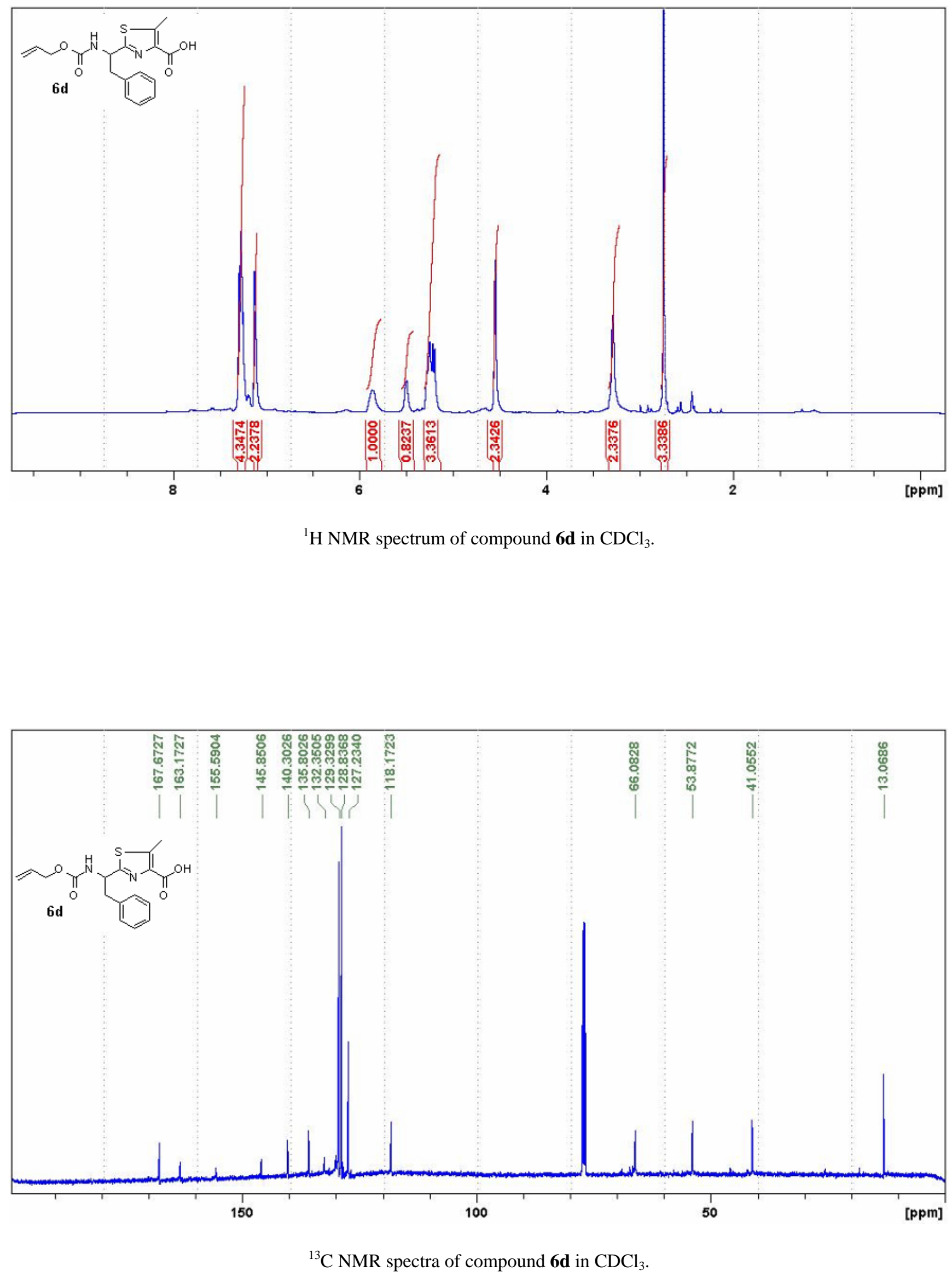

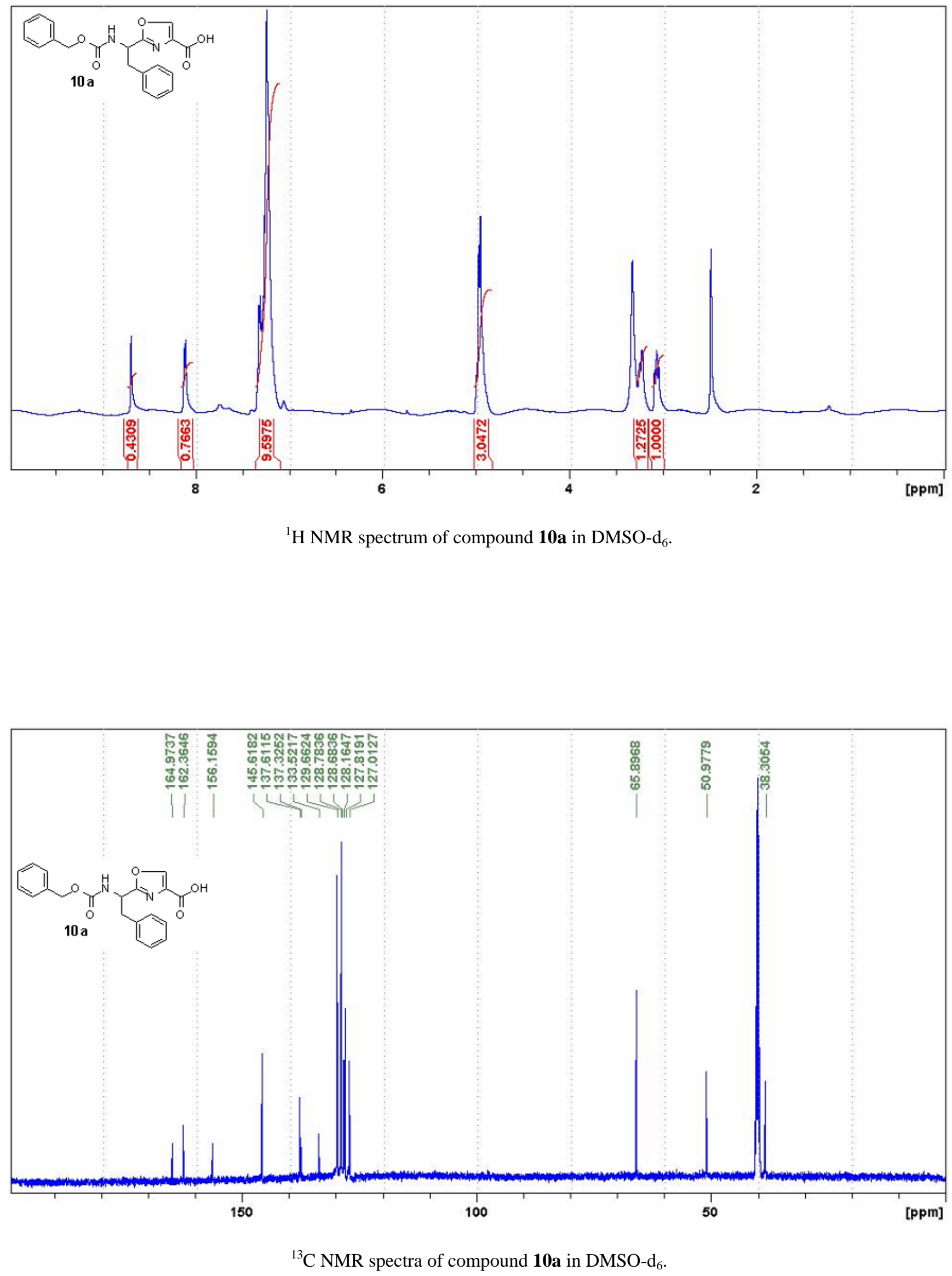

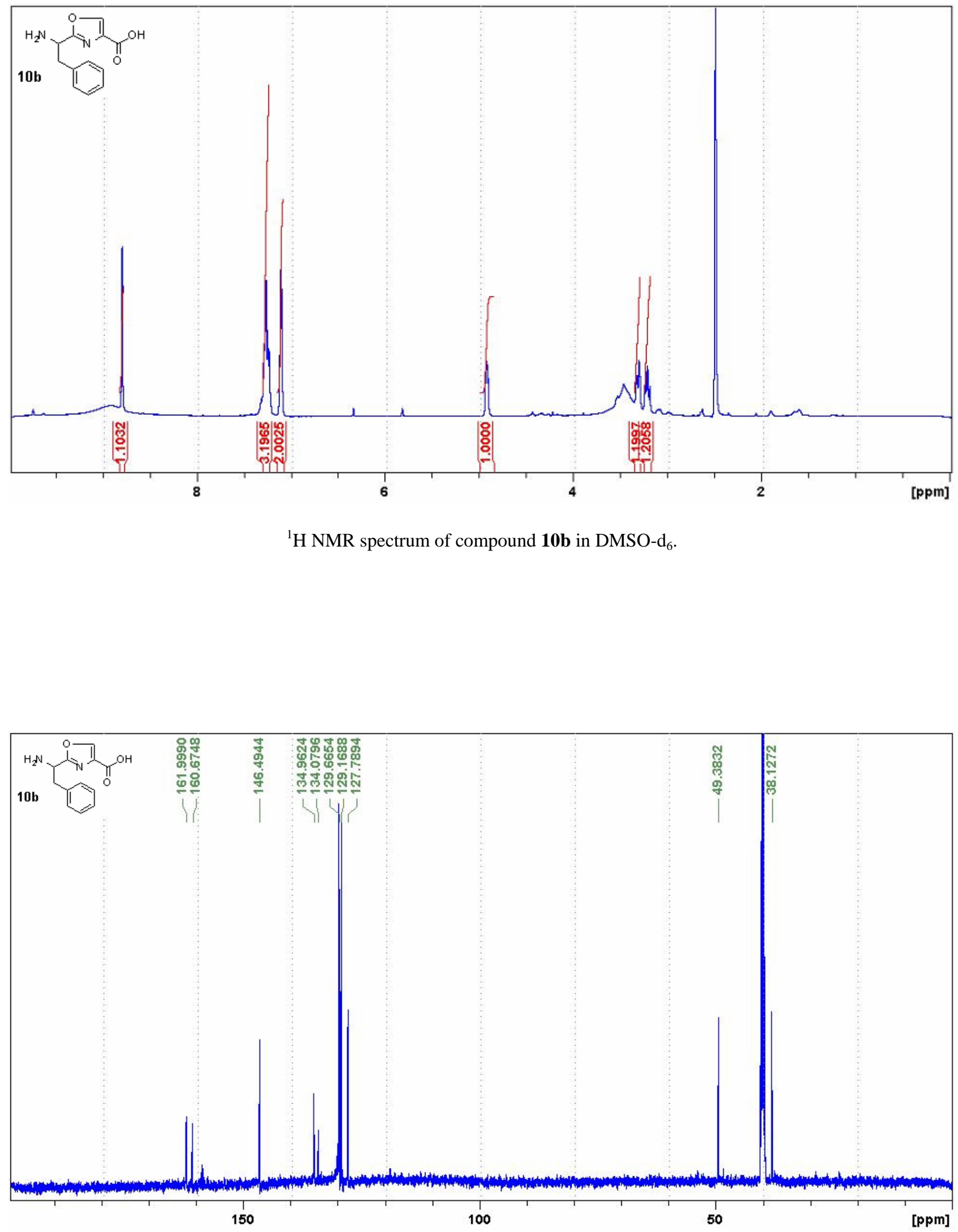

${ }^{13} \mathrm{C}$ NMR spectra of compound $\mathbf{1 0 b}$ in DMSO- $\mathrm{d}_{6}$. 


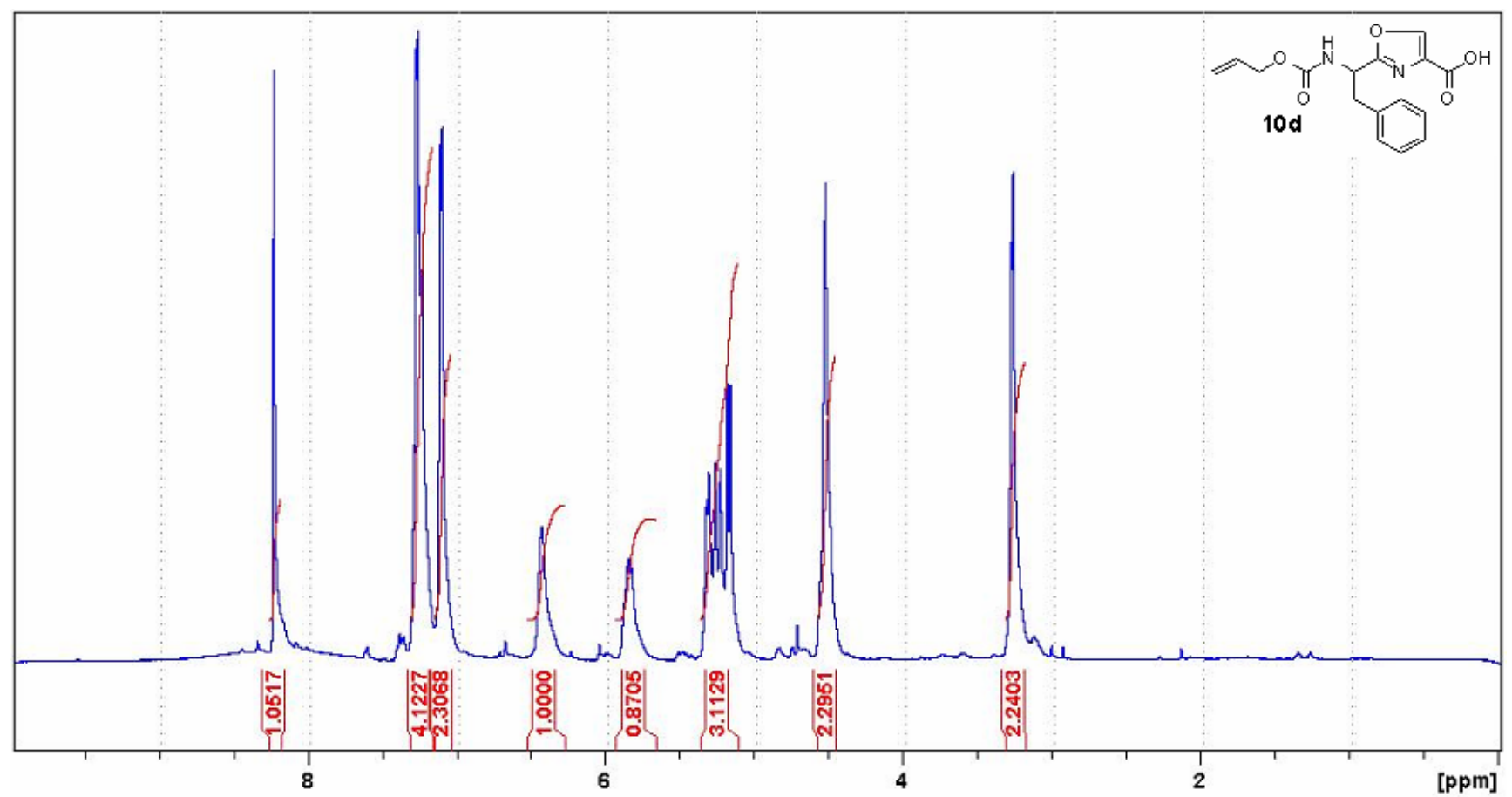

${ }^{1} \mathrm{H}$ NMR spectrum of compound $\mathbf{1 0 d}$ in $\mathrm{CDCl}_{3}$.

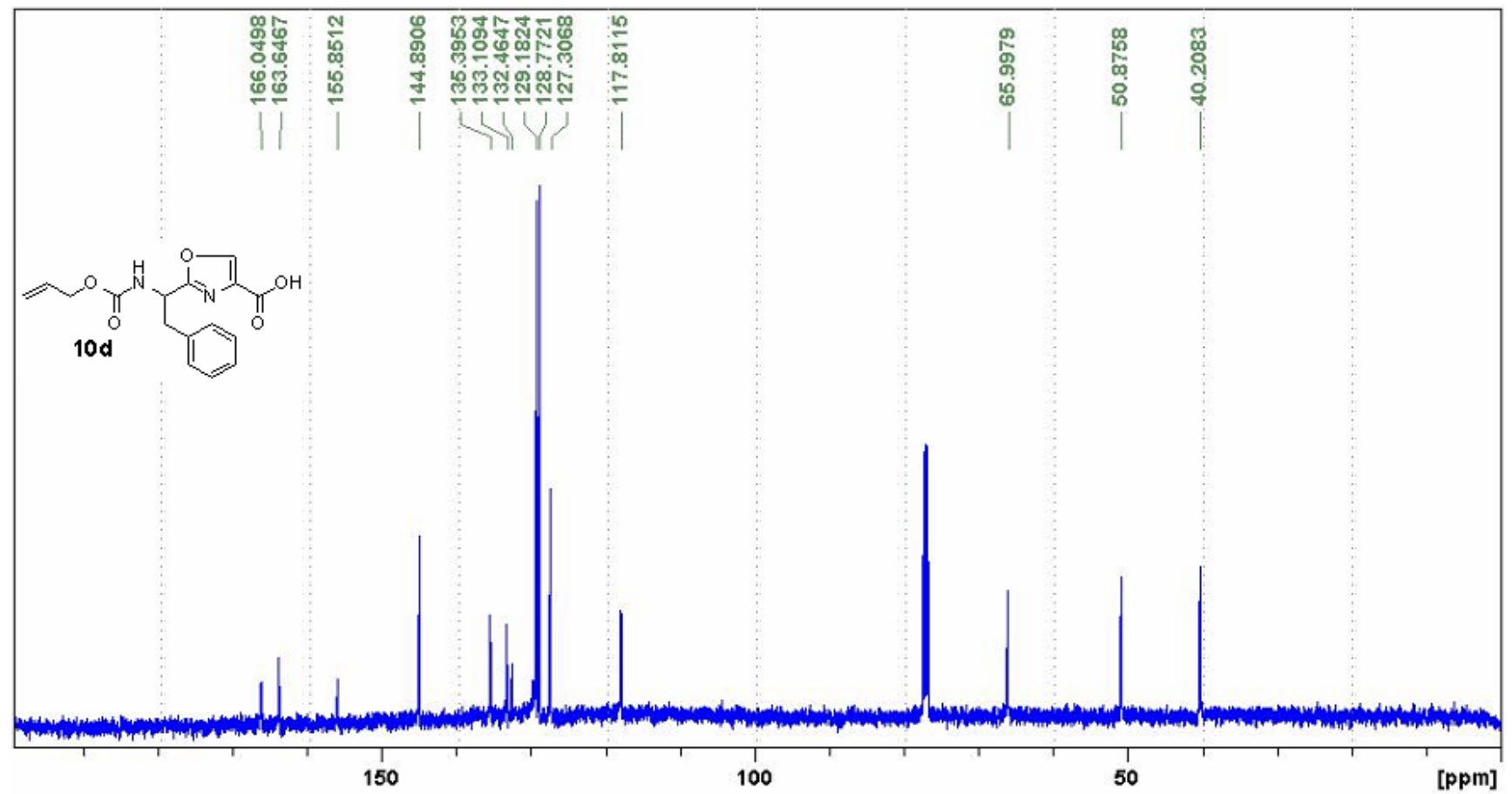

${ }^{13} \mathrm{C}$ NMR spectra of compound $\mathbf{1 0 d}$ in $\mathrm{CDCl}_{3}$. 

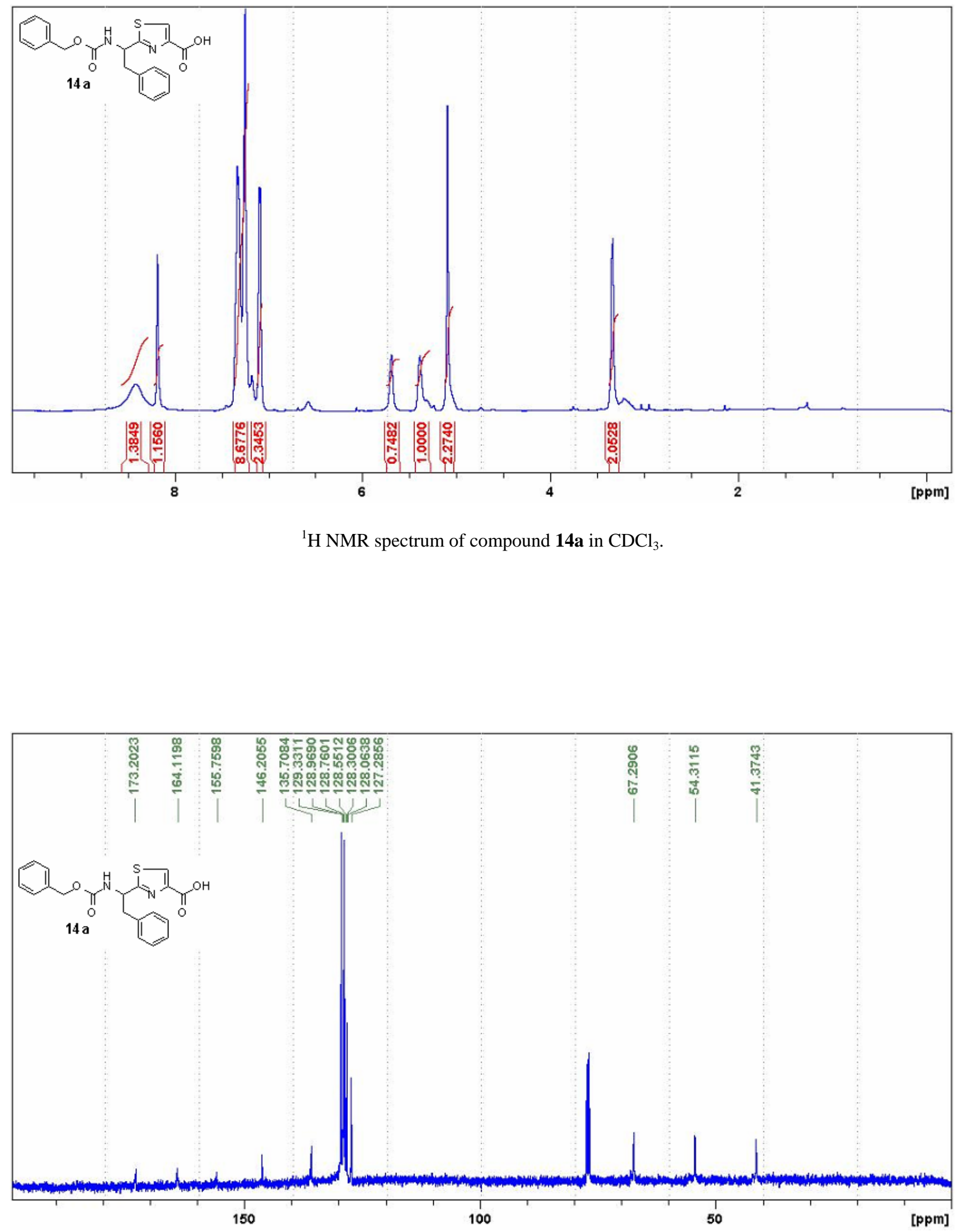

${ }^{13} \mathrm{C}$ NMR spectra of compound 14a in $\mathrm{CDCl}_{3}$. 

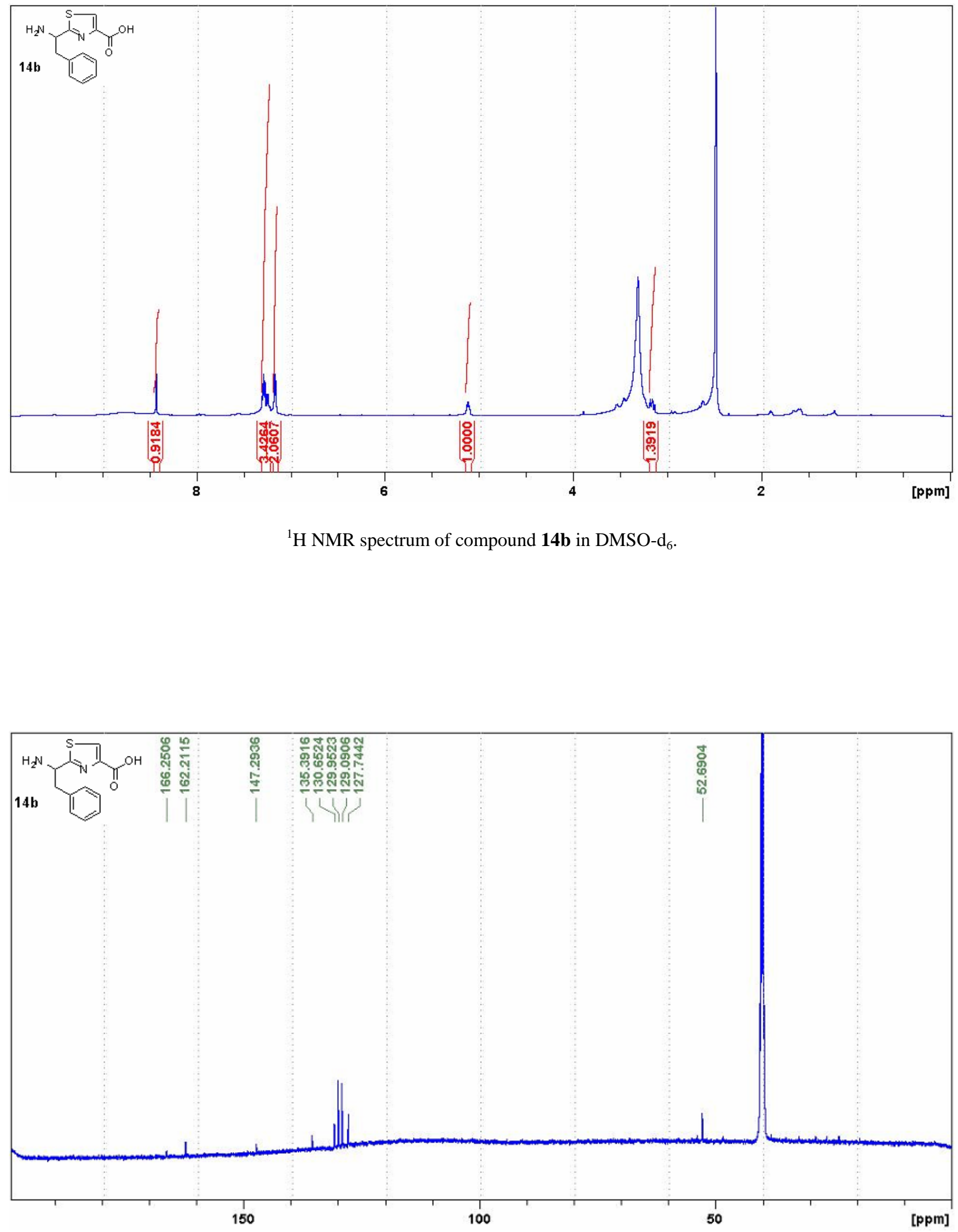

${ }^{13} \mathrm{C}$ NMR spectra of compound $\mathbf{1 4 b}$ in DMSO- $\mathrm{d}_{6}$. 

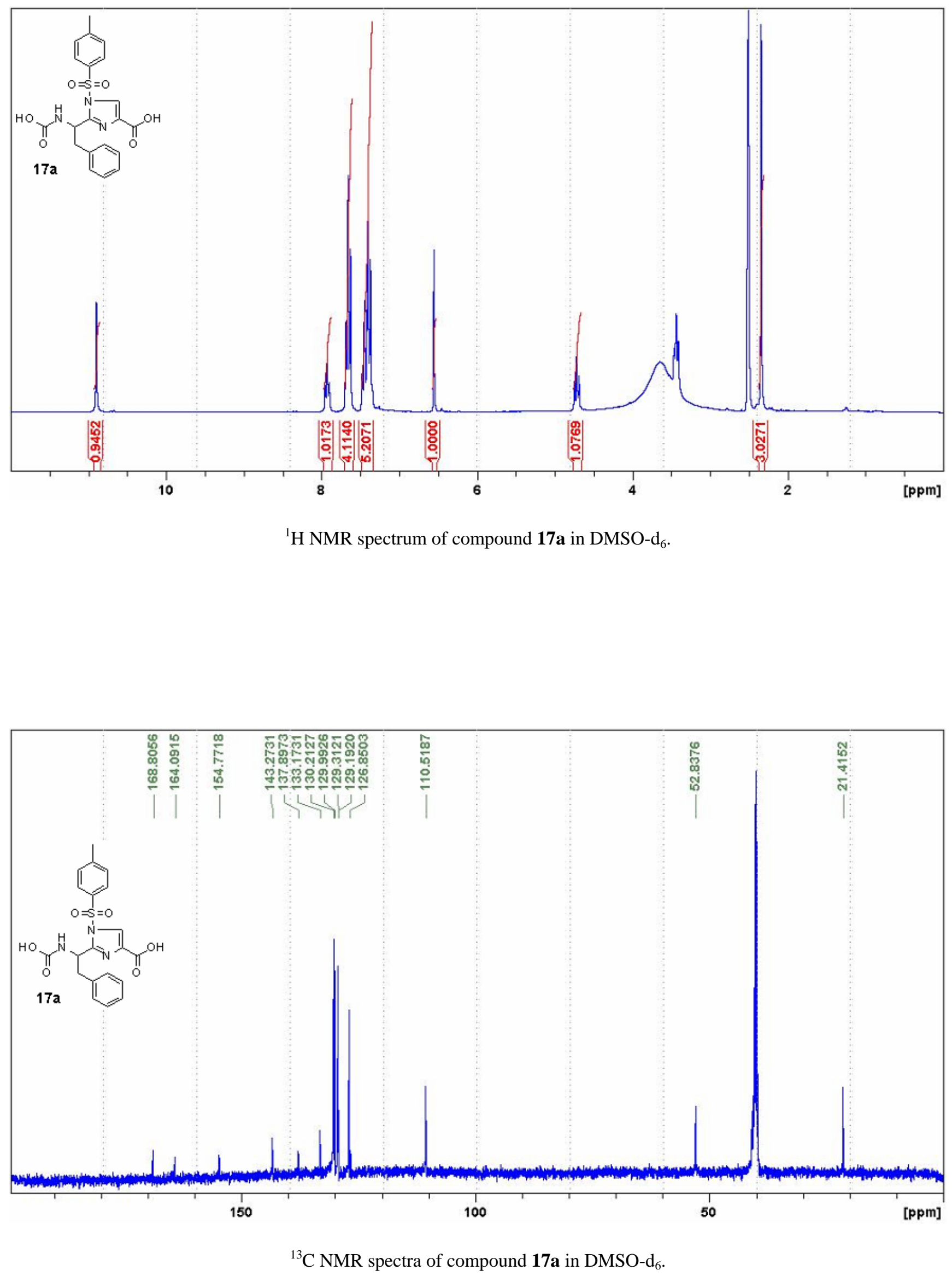


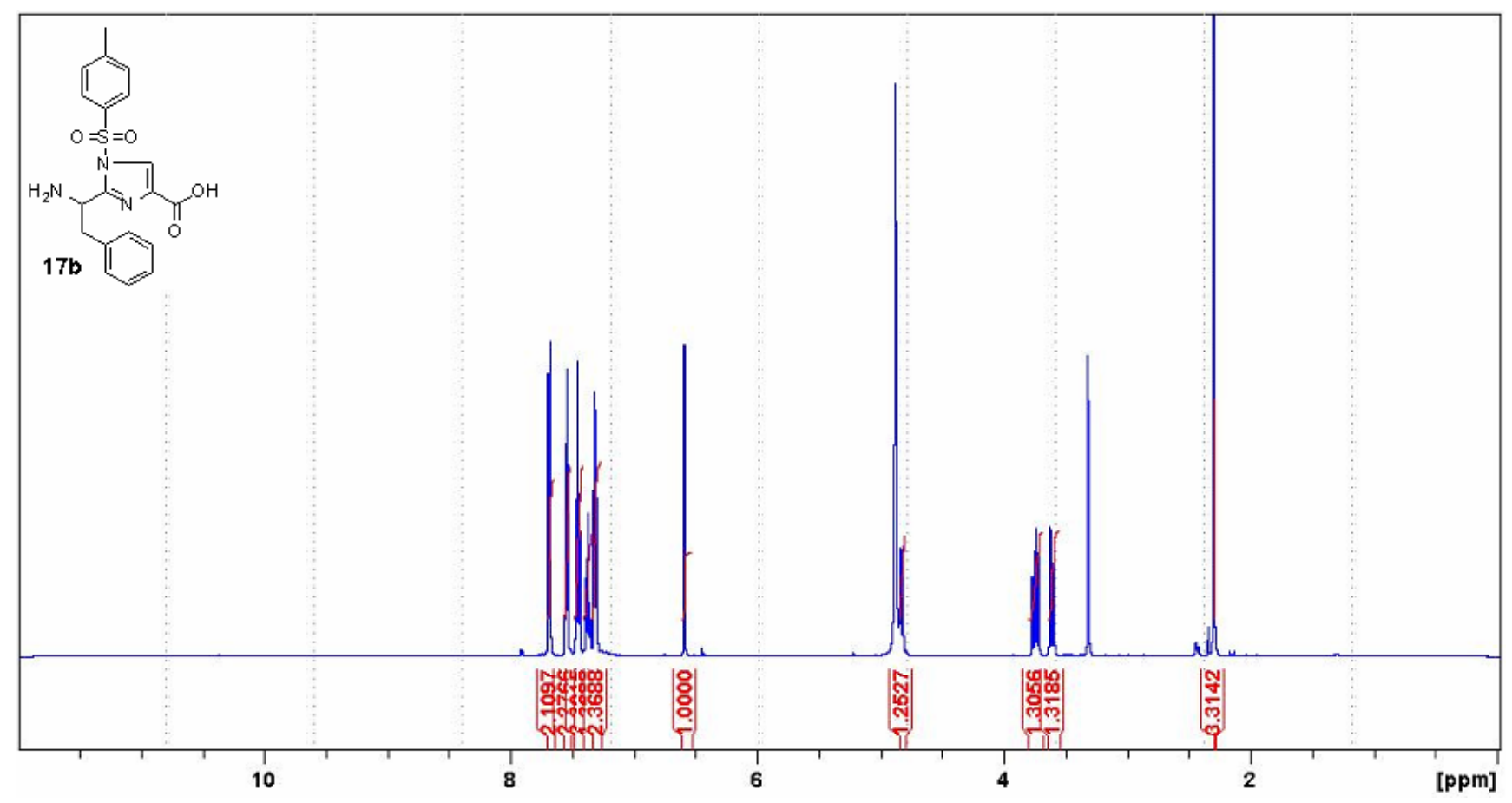

${ }^{1} \mathrm{H}$ NMR spectrum of compound $\mathbf{1 7 b}$ in $\mathrm{CD}_{3} \mathrm{OD}$.

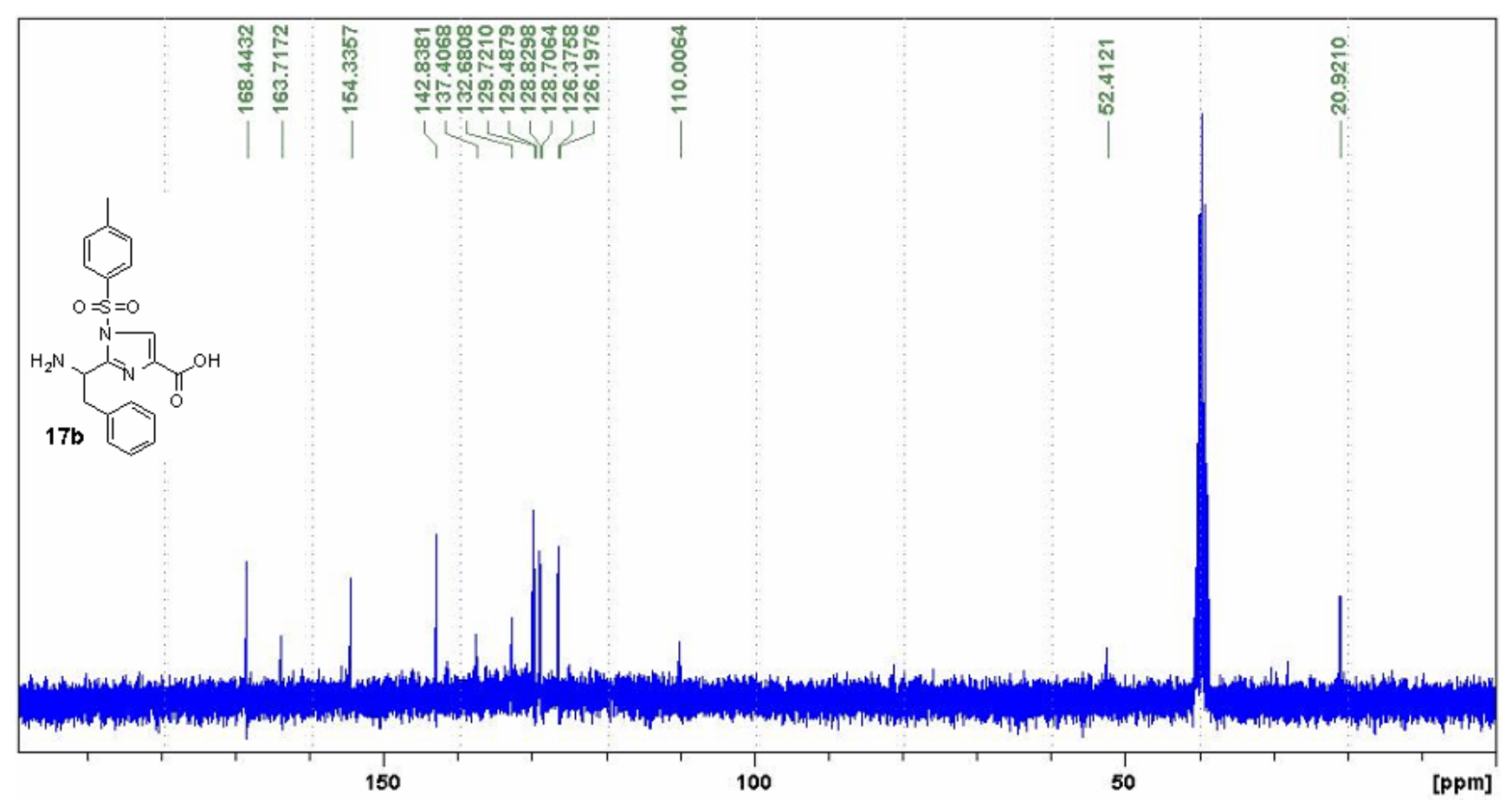

${ }^{13} \mathrm{C}$ NMR spectra of compound $\mathbf{1 7} \mathbf{b}$ in DMSO- $\mathrm{d}_{6}$. 

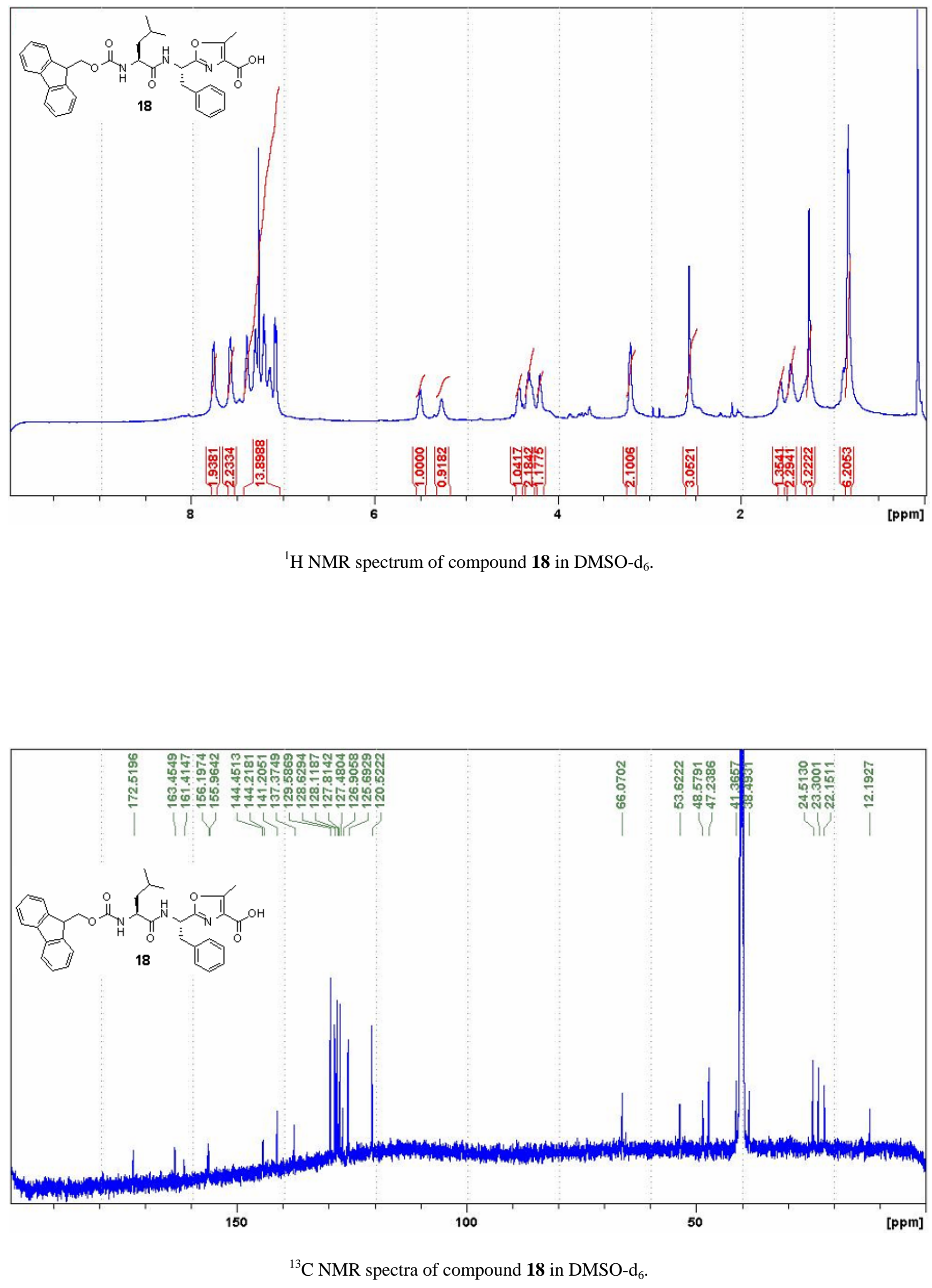


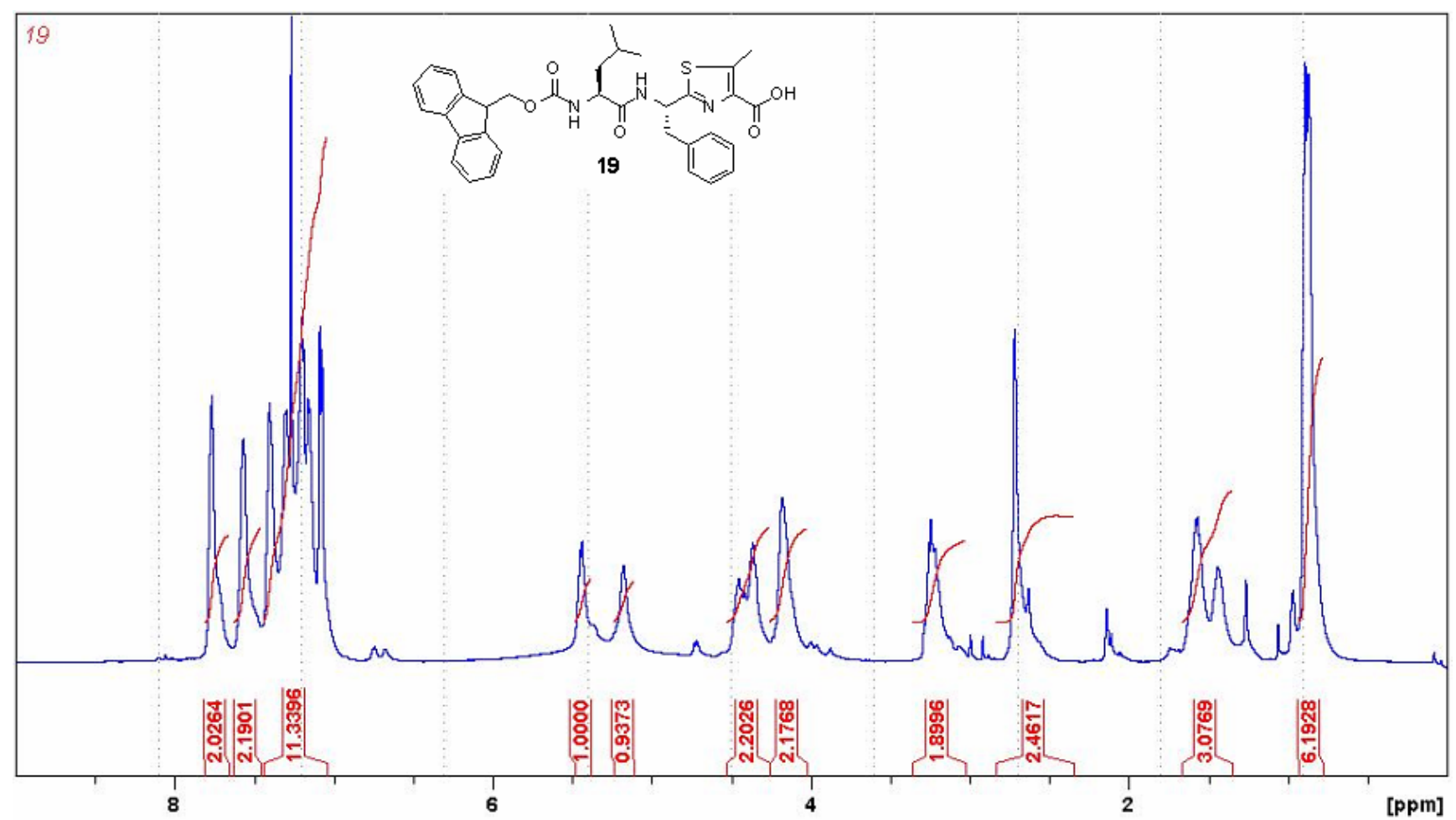

${ }^{1} \mathrm{H}$ NMR spectrum of compound 19 in DMSO- $\mathrm{d}_{6}$.

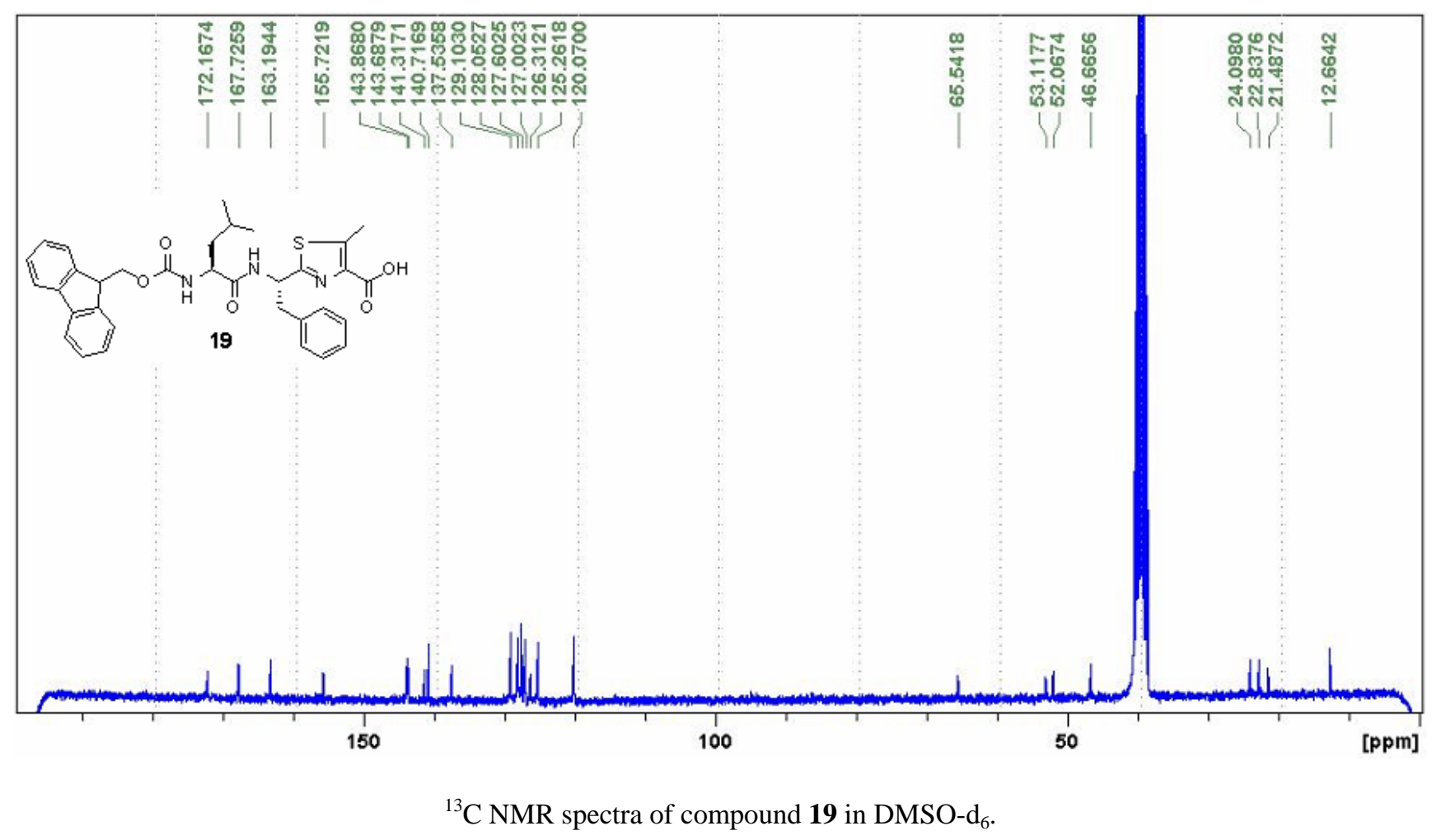




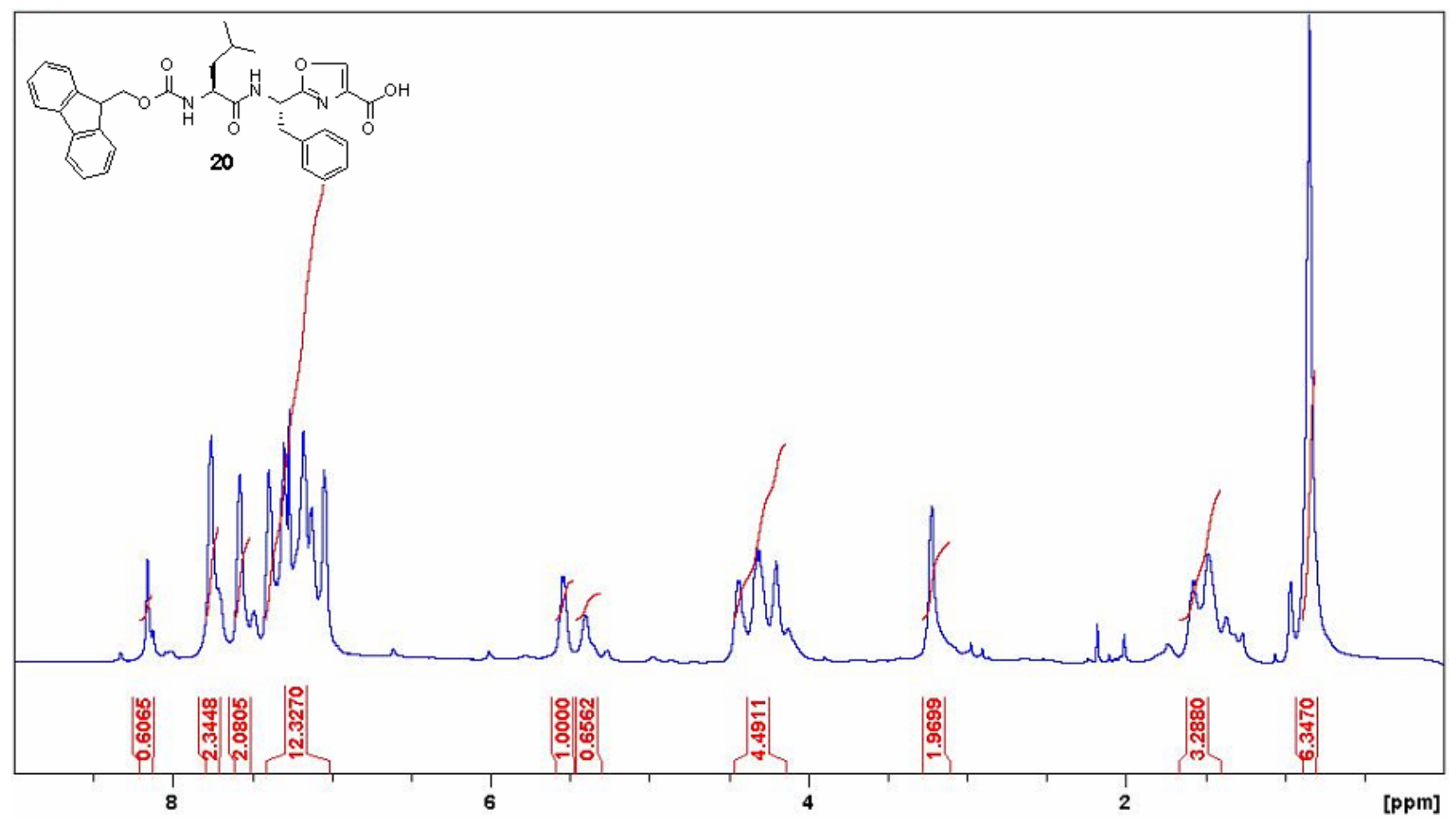

${ }^{1} \mathrm{H}$ NMR spectrum of compound 20 in $\mathrm{CDCl}_{3}$.

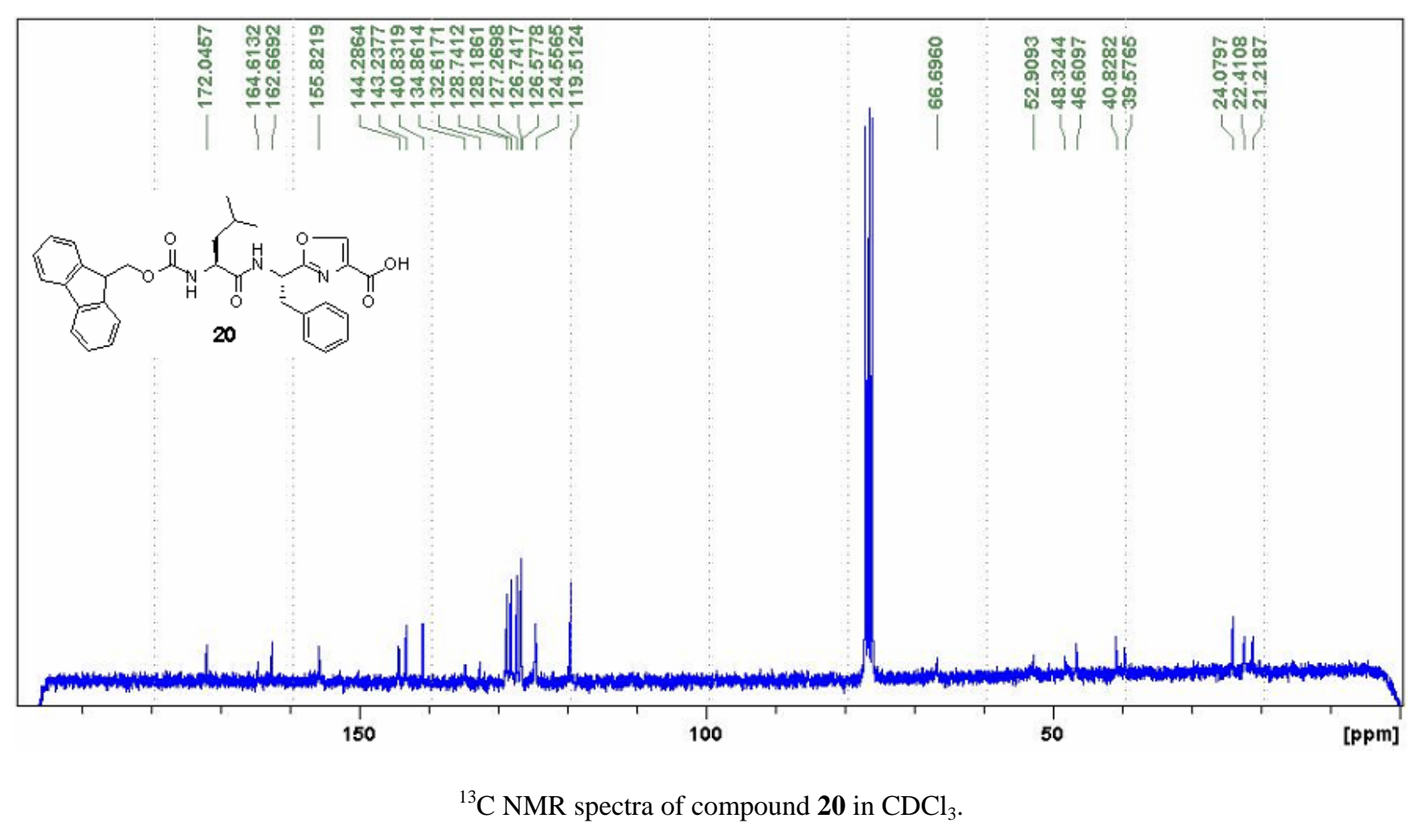




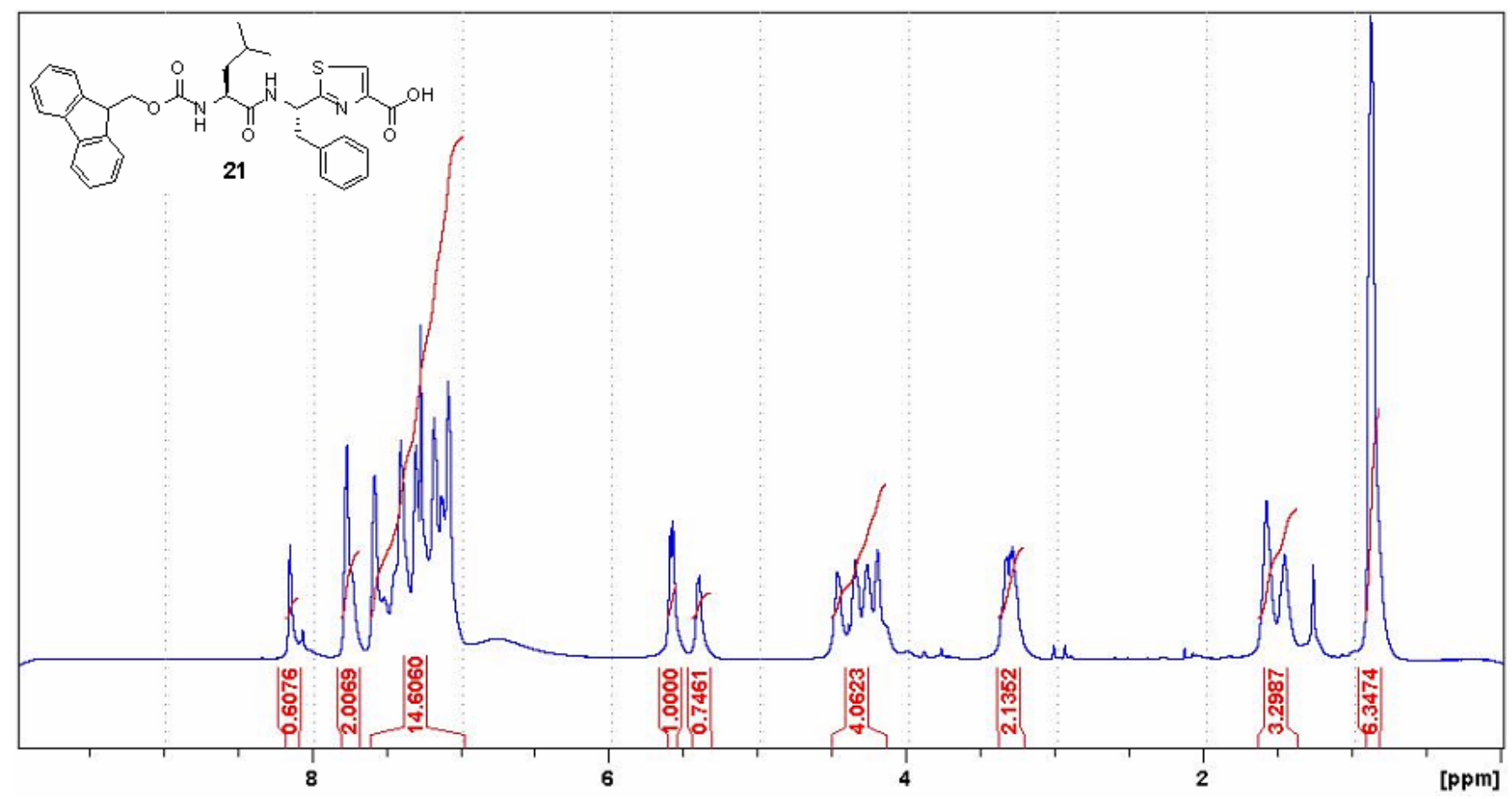

${ }^{1} \mathrm{H}$ NMR spectrum of compound 21 in $\mathrm{CDCl}_{3}$.

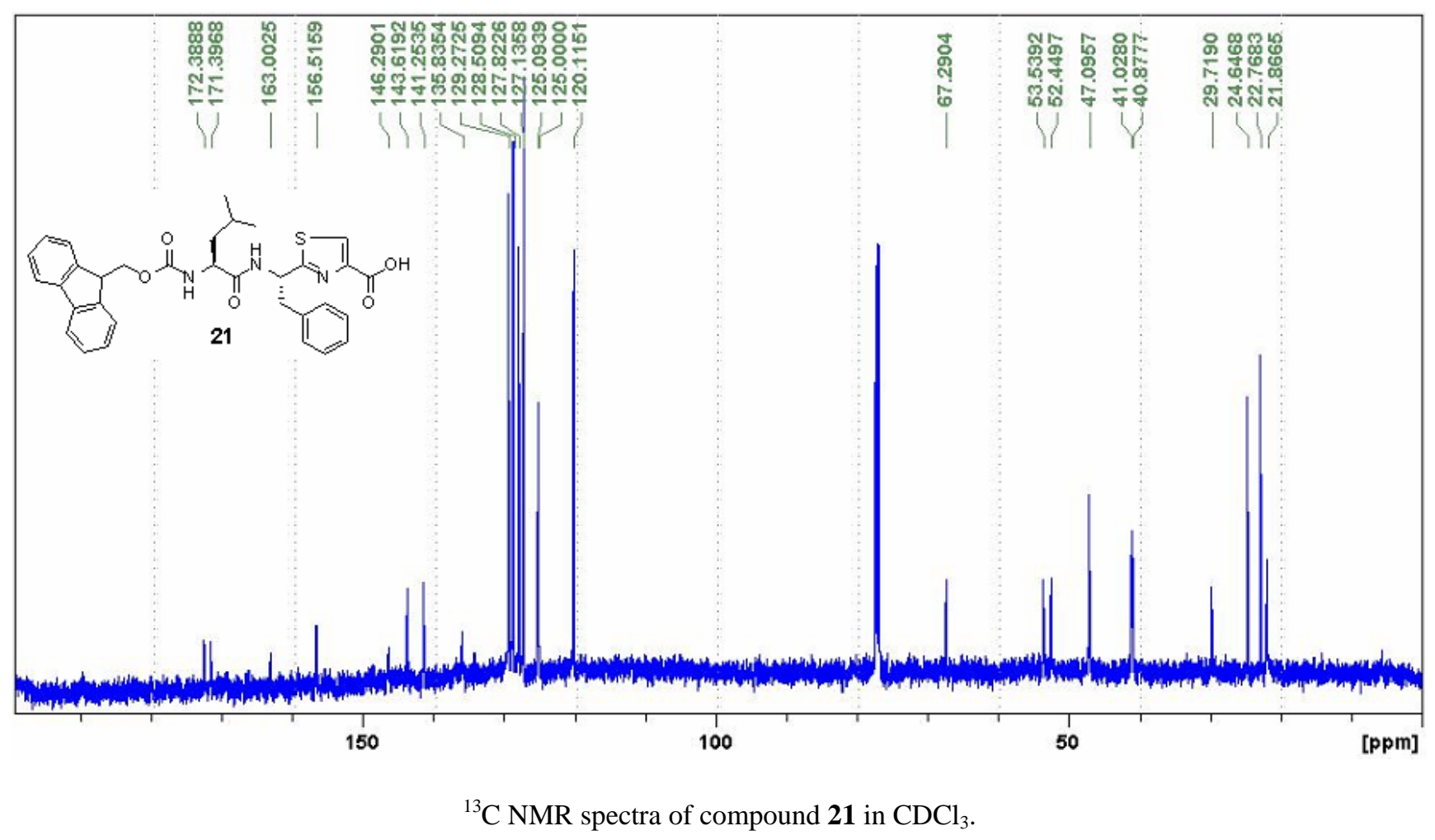




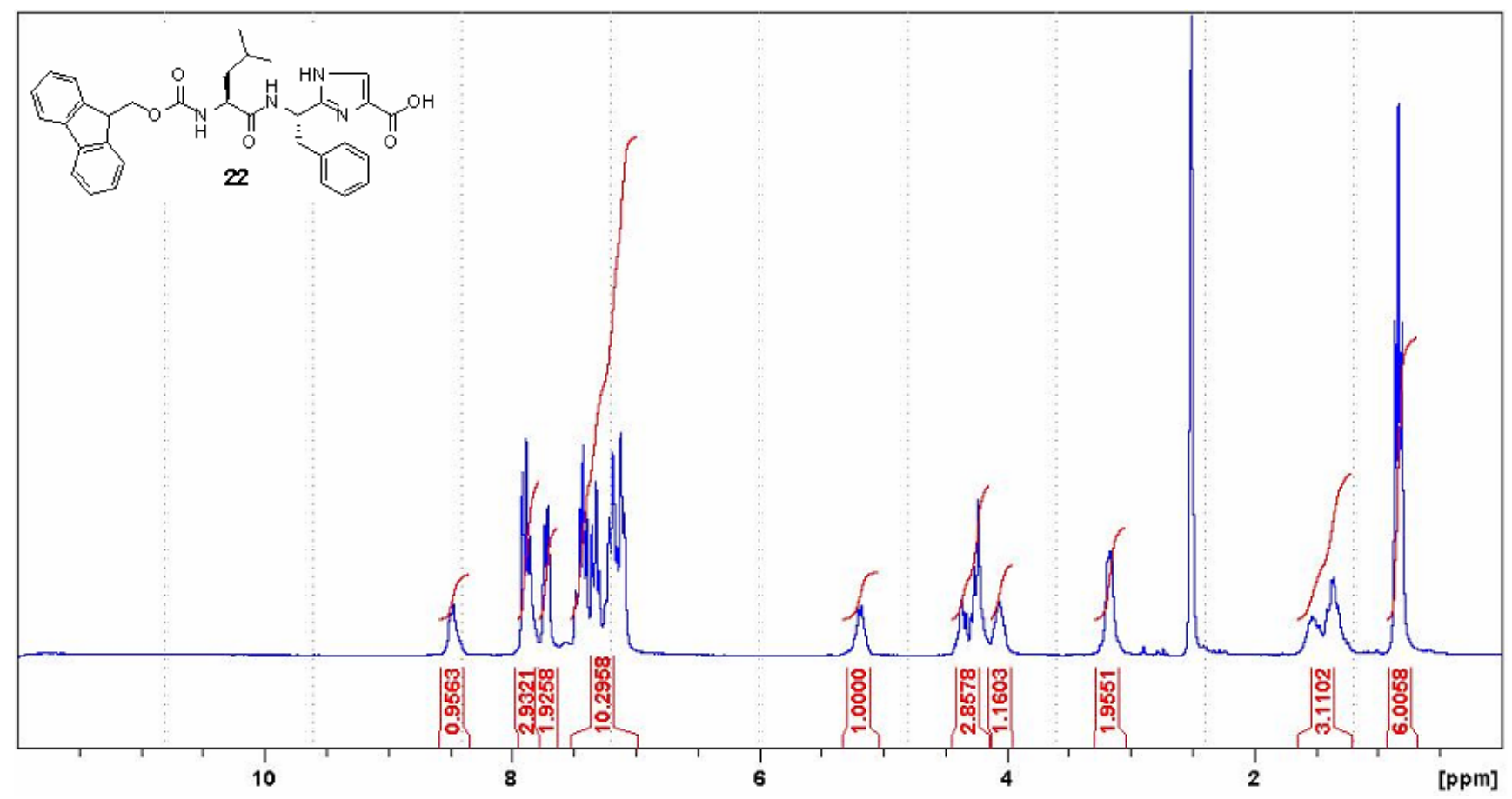

${ }^{1} \mathrm{H}$ NMR spectrum of compound 22 in DMSO- $\mathrm{d}_{6}$.

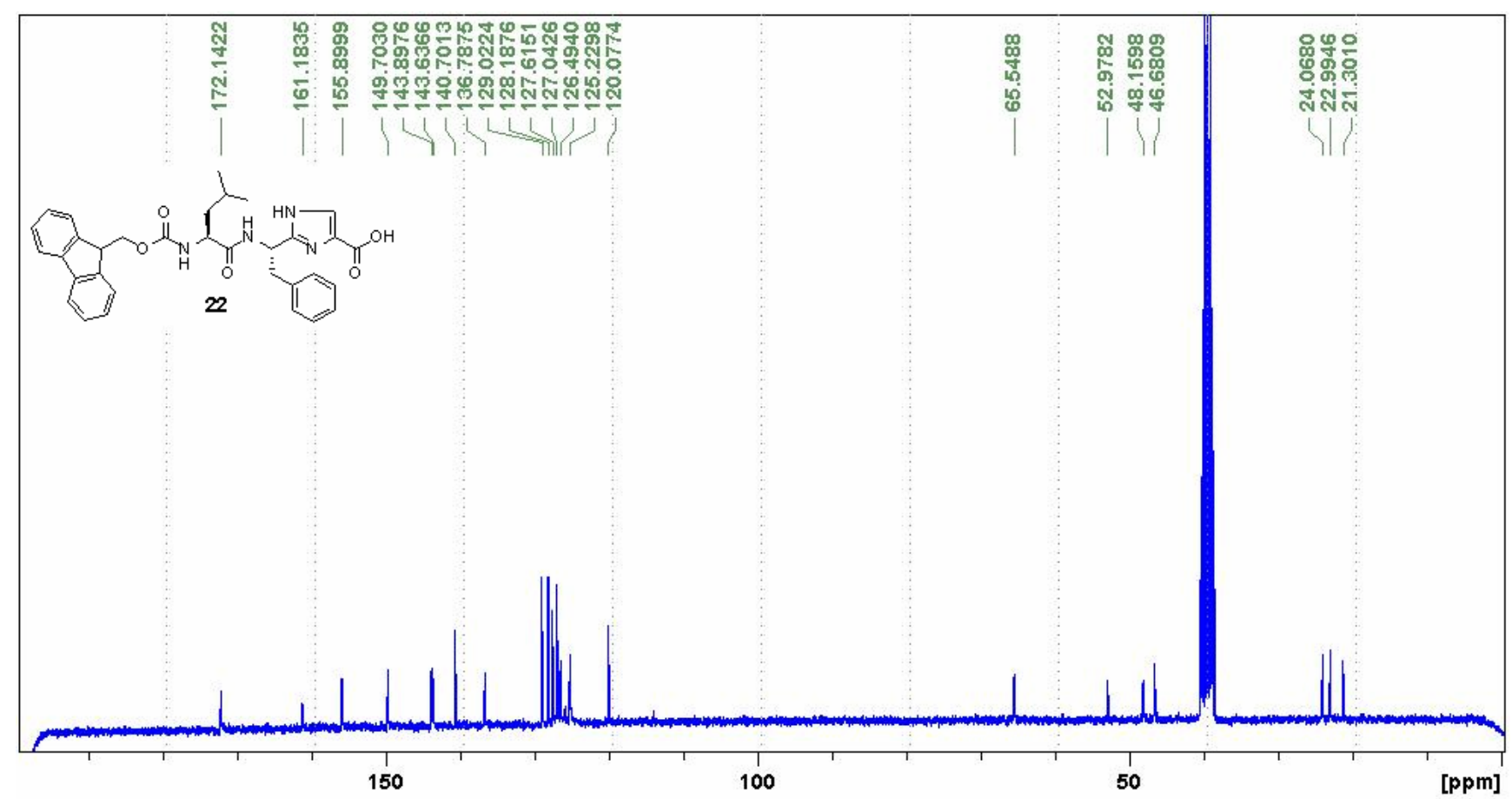

${ }^{13} \mathrm{C}$ NMR spectra of compound 22 in DMSO- $\mathrm{d}_{6}$. 